
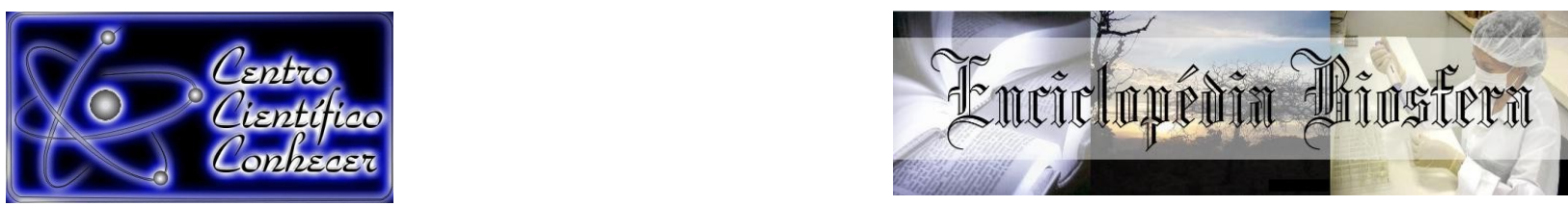

\title{
SUPERAÇÃO DE DORMÊNCIA EM SEMENTES DE Schizolobium amazonicum Ducke
}

${ }^{1}$ José Maria Moura de Negreiros, ${ }^{2}$ Alan Augusto Nobre Feitosa, ${ }^{3}$ Sabrina Silva de Oliveira, ${ }^{4}$ Josimar Batista Ferreira, ${ }^{5}$ Gleisson de Oliveira Nascimento

${ }^{1}$ Graduando em Agroecologia do Instituto Federal do Acre - IFAC.

${ }^{2}$ Prof. Msc. do Instituto Federal do Acre - IFAC.

${ }^{3}$ Graduanda em Engenharia Florestal da Universidade Federal do Acre - UFAC.

${ }^{4}$ Prof. Dr. da Universidade Federal do Acre - UFAC, Rio Branco-AC-Brasil (josimarferreira@gmail.com).

${ }^{5}$ Doutorando em Ciências de Florestas Tropicais do Instituto Nacional de Pesquisas da Amazônia - INPA.

Recebido em: 08/09/2015 - Aprovado em: 14/11/2015 - Publicado em: 01/12/2015 DOI: http://dx.doi.org/10.18677/Enciclopedia_Biosfera_2015_227 dormência tegumentar que pode ser superada por métodos pré-germinativos. Neste trabalho, objetivou-se avaliar tratamentos pré-germinativos visando identificar o método mais eficiente para superar a dormência de sementes de paricá ( $S$. amazonicum) e acelerar sua germinação. Realizaram-se diferentes testes de superação de dormência, no intuito de identificar o melhor método, por meio dos seguintes tratamentos: Imersão em ácido sulfúrico (60 minutos) - $T_{1}$, imersão em água (24 horas) - $T_{2}$ e escarificação mecânica - $T_{3}$. No tratamento controle - $T_{0}$ foram utilizadas sementes que não sofreram superação de dormência. Verificou-se que escarificação mecânica e imersão em ácido sulfúrico foram os tratamentos que proporcionaram a germinação em menor intervalo de tempo.

PALAVRAS-CHAVE: Germinação; escarificação mecânica; Paricá; Tratamentos prégerminativos

\section{OVERCOMING DORMANCY IN Schizolobium amazonicum Ducke SEEDS}

ABSTRACT

Seeds of Schizolobium amazonicum Ducke presents physical dormancy which can be broken through different pre-germinative methods. This study aimed to assess pre-germinative treatments to identify the most efficient method to overcome the dormancy of parica (S. amazonicum) and accelerate its germination. There was different tests to identify the best method, by means of the following treatments: immersion in sulfuric acid (60 minutes) - $T_{1}$, water immersion (24 hours) - $T_{2}$ and mechanical chiseling - $T_{3}$. Were used seeds without dormancy breaking treatment for the control group - $T_{0}$. It 
was found that seeds subjected to mechanical chiseling and soaking in sulfuric acid germinated in less time.

KEYWORDS: Parica; Pre-germinative treatments; Germination; Mechanical scarification.

\section{INTRODUÇÃO}

O paricá (Schizolobium amazonicum Ducke) é uma espécie florestal que ocorre em todo o Brasil, com exceção da Região Sul, encontrando-se na Amazônia brasileira em florestas maduras e secundárias de terra firme e várzea alta, principalmente nos estados do Pará, Rondônia, Amazonas, Mato Grosso (CARVALHO \& VIÉGAS, 2004) e também no estado do Acre (LOBÃO et al., 2012). As árvores chegam a aproximadamente $40 \mathrm{~m}$ de altura e $100 \mathrm{~cm}$ de diâmetro na idade adulta; seu tronco é reto, e em algumas situações, apresentam sapopemas basais (CARVALHO, 2007). O potencial silvicultural e tecnológico investigados nos últimos anos confirmam a viabilidade desta espécie para o reflorestamento (VIDAURRE et al., 2012).

A madeira de $S$. amazonicum é leve e de processamento fácil. É considerada de viabilidade técnica para produção de painéis (IWAKIRI et al., 2012). Além disso, essa espécie é indicada para recuperação de áreas degradadas e pode fornecer matériaprima para produção de papel e celulose, devido a seu fácil branqueamento e as excelentes resistências obtidas com o papel (CARVALHO \& VIÉGAS, 2004). No Brasil, existem em torno de 80.470 ha com plantios de paricá, considerando os estados do Pará, Maranhão e Tocantins (ABRAF, 2012), e atualmente há um crescente interesse pelo cultivo desta espécie devido seu bom desempenho volumétrico principalmente em sistemas agroflorestais (CORDEIRO et al., 2015).

O S. amazonicum tem sido recomendado para plantios comerciais e, por essa razão, é grande a demanda por mudas desta espécie (SHIMIZU et al., 2011). Entretanto, as informações acerca do comportamento de espécies florestais da região Amazônica, principalmente com relação à tecnologia para produção de sementes e mudas florestais ainda são insuficientes (MONTEIRO et al., 2010).

A fase de produção de mudas é considerada de grande importância para o estabelecimento dos plantios florestais (CAIONE et al., 2012). No entanto, algumas espécies retardam a germinação de suas sementes, até que as condições do ambiente estejam adequadas para o seu estabelecimento e sobrevivência (AZEREDO et al., 2010), o que muitas vezes inviabiliza a obtenção de mudas a partir de sementes em viveiros (PUKACKA \& RATAJCZAK, 2014). Além disso, a dormência causa desuniformidade na germinação e dificulta a obtenção de população de plantas adequadas na implantação da cultura (KOBORI et al., 2013).

A redução do tempo de emergência pela superação de dormência pode também diminuir o tempo de exposição das sementes a fungos e outros patógenos (DALLING et al., 2011) e a animais predadores que são fatores limitantes à dispersão e posterior estabelecimento de espécies de árvores (PEREIRA et al., 2013).

Nesta perspectiva, torna-se essencial estudar métodos adequados para análise de sementes, no intuito de auxiliar na produção de mudas de espécies florestais. Portanto, o objetivo com este trabalho foi avaliar diferentes tratamentos prégerminativos visando identificar o método mais eficiente para superar a dormência de sementes de paricá (S. amazonicum) e acelerar sua germinação. 


\section{MATERIAL E MÉTODOS}

O experimento foi conduzido na Universidade Federal do Acre, Campus Floresta em Cruzeiro do Sul-AC, situado a 214 m de altitude, lat 70³6'66"L e long 7240"52"O. O clima desta região é classificado como equatorial Af (classificação de Köppen), sem ocorrência de estação seca (ALVARES et al., 2013).

As sementes de paricá ( $S$. amazonicum) foram adquiridas junto a Fundação de Tecnologia do Estado do Acre - FUNTAC, e o experimento montado logo após sua obtenção. As sementes foram submetidas a diferentes métodos de superação de dormência, no intuito de identificar o melhor método, por meio dos seguintes tratamentos: To-controle, $\mathrm{T}_{1}$-Imersão em ácido sulfúrico $\left(\mathrm{H}_{2} \mathrm{SO}_{4}\right)$ durante 60 minutos, sendo depois lavadas em água destilada, $\mathrm{T}_{2}$-imersão em água por 24 horas e $\mathrm{T}_{3^{-}}$ escarificação mecânica em lixa (três estrias por semente) na região oposta ao eixo embrionário (SHIMIZU et al., 2011). No tratamento $\mathrm{T}_{0}$-controle, foram utilizadas sementes isentas de tratamento para superação de dormência.

Após a submissão aos tratamentos para superação de dormência, as sementes foram dispostas em bandejas plásticas, com a utilização de areia esterilizada em autoclave, durante 20 minutos em temperatura de $120^{\circ} \mathrm{C}$, dando início ao acompanhamento da germinação. Realizaram-se irrigações diárias para a manutenção da umidade em níveis ótimos para a germinação. A avaliação da germinação das sementes foi realizada em ambiente protegido de chuvas. Foram contabilizados os indivíduos germinados segundo o método estabelecido no manual de Regras para Análise de Sementes - RAS (BRASIL, 2009). As sementes não germinadas foram submetidas ao método de corte longitudinal, sendo então analisadas visualmente para verificação do conteúdo interno (BRASIL, 2009).

$\mathrm{O}$ delineamento experimental utilizado foi o inteiramente casualisado $(4 \times 6)$, com quatro tratamentos, sendo seis repetições (bandejas) por tratamento. Cada repetição (bandeja) foi composta por 25 sementes, totalizando 150 sementes para cada tratamento. A contagem das sementes foi acompanhada até uma semana após a germinação total de um dos tratamentos utilizados neste estudo.

Neste trabalho foi realizado o ajuste do tempo de emergência para Schizolobium amazonicum com o software germinator $₫$ (JOOSEN et al., 2010), conforme descrito por EL-KASSABY et al. (2008) utilizando os parâmetros da função Hill (4PHF), conforme Equação 1:

$$
y=y_{o}+\frac{a x^{b}}{c^{b}+x^{b}}
$$

Em que:

$y=$ porcentagem de emergência cumulativa em $x$ tempo;

$y_{0}=$ interceptação no eixo y;

$b=$ expoente que controla a forma e grau de inclinação da curva;

$c=$ tempo necessário para $50 \%$ dos propágulos viáveis emergirem (t50);

$x=$ tempo;

$a$ = máximo de porcentagem de emergência cumulativa. 
Neste estudo, desconsiderou-se o ajuste para o tratamento controle $-T_{0}$, tendo em vista o baixo número de sementes germinadas para este tratamento. $O$ número de sementes germinadas para cada tratamento foi submetido à análise de variância e as médias comparadas pelo teste Scott Knott ao nível de $1 \%$ de probabilidade utilizando o programa estatístico SISVAR ${ }^{\circledR}$ (FERREIRA, 2011).

\section{RESULTADOS E DISCUSSÃO}

De acordo com os dados de germinação dos indivíduos submetidos aos diferentes métodos de superação de dormência, as maiores porcentagens de germinação em menor tempo ocorreram quando as sementes foram submetidas aos tratamentos de escarificação mecânica $\left(T_{3}\right)$ e imersão em ácido sulfúrico $\left(T_{1}\right)$ durante 60 minutos (Tabela 1 e Figura 1). No entanto, o uso de ácido sulfúrico é considerado insalubre, limitando a recomendação desta técnica para produtores rurais (SHIMIZHU et al., 2011).

TABELA - 1: Dados absolutos de germinação obtidos para os diferentes métodos de superação de dormência em Schizolobium amazonicum Ducke.

\begin{tabular}{lcc}
\hline \multicolumn{1}{c}{ Tratamentos } & $\begin{array}{c}\text { Total de sementes } \\
\text { germinadas }\end{array}$ & $\begin{array}{c}\text { Percentual de sementes } \\
\text { germinadas }\end{array}$ \\
\hline $\mathrm{T}_{0}$ - Tratamento controle & 3 & 2 \\
$\mathrm{~T}_{1}-$ Imersão em ácido \\
sulfúrico $\left(\mathrm{H}_{2} \mathrm{SO}_{4}\right) / 60$ min. & 120 & 80 \\
$\mathrm{~T}_{2}$-imersão em água/24 $\mathrm{h}$ & 6 & 4 \\
$\mathrm{~T}_{3}$-escarificação mecânica & 150 & 100 \\
\hline
\end{tabular}

No geral, apenas o método de escarificação mecânica possibilitou a obtenção de $100 \%$ de emergência durante o período de avaliação (Tabela 1). A distribuição do tempo de germinação entre os tratamentos de imersão em ácido sulfúrico $\left(\mathrm{H}_{2} \mathrm{SO}_{4}\right) / 60$ minutos $\left(T_{1}\right)$ e imersão em água/24 horas $\left(T_{2}\right)$ ocorreram de forma semelhantes (Figura 1), porém em quantidades diferenciadas, sendo um total de 120 sementes germinadas para o primeiro e seis para o segundo tratamento (Tabela 1). No tratamento controle $\left(T_{0}\right)$, ocorreu a germinação de apenas três sementes de paricá. Portanto, os tratamentos pré-germinativos possibilitaram diferentes quantidades de germinação para sementes de $S$. amazonicum. Após o corte longitudinal das sementes não germinadas identificaram-se boas condições visuais com relação ao conteúdo do cotilédone, verificando-se ausência de ataques de patógenos ou pragas, e também de sementes vazias dentre as amostras. 


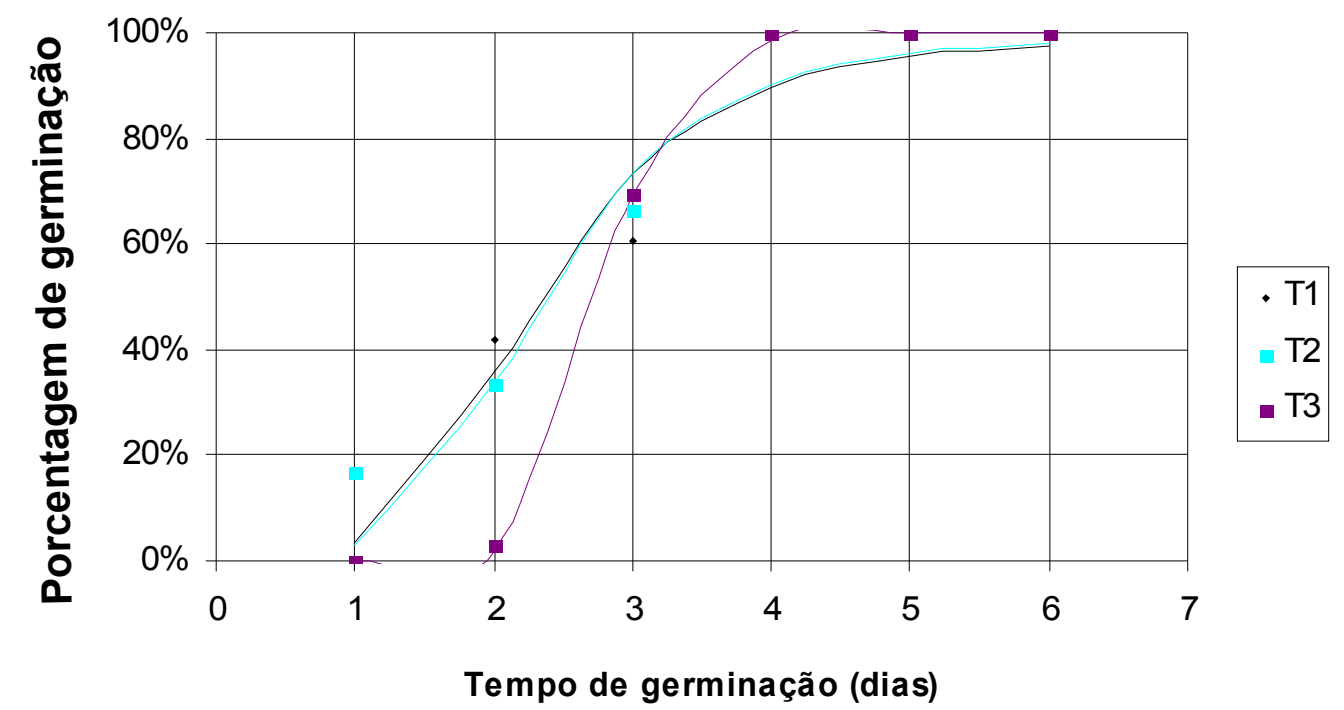

FIGURA 1: Tempo de germinação de sementes de paricá (Schizolobium amazonicum) sob diferentes métodos de superação de dormência. $\mathrm{T}_{1}$ - Imersão em ácido sulfúrico $\left(\mathrm{H}_{2} \mathrm{SO}_{4}\right)$ durante 60 minutos; $\mathrm{T}_{2}$ Imersão em água $\left(\mathrm{H}_{2} \mathrm{O}\right)$ durante 24 horas; $\mathrm{T}_{3}$ - Escarificação mecânica. $T_{0}$ - controle foi desconsiderado devido à baixa quantidade de sementes germinadas. $R^{2}$ médio=0,92.

O máximo de germinação foi alcançado após quatro dias para escarificação mecânica, sendo que este tratamento proporcionou menor tempo para germinação (Figura 1) e foi o único tratamento que possibilitou a germinação de $100 \%$ das sementes. SHIMIZU et al. (2011) afirmaram atingir 100\% de germinação de sementes de paricá sob a influência da escarificação mecânica após oito dias. Vale ressaltar que, a escarificação para esta análise foi realizada com a abertura de três estrias em cada semente, o que favoreceu maior entrada de água no tegumento. Nesse sentido, o manuseio e a intensidade do tratamento podem influenciar na quantidade e tempo de germinação de sementes das espécies florestais.

O sucesso da superação de dormência em sementes de paricá (S. amazonicum), com os tratamentos de escarificação mecânica e imersão em ácido sulfúrico podem ter sido em decorrência da promoção da entrada de água no tegumento após a submissão das sementes aos referidos tratamentos, acelerando assim o processo de germinação (MEIRELES et al., 2007).

O tratamento de imersão em água por 24 horas $\left(T_{2}\right)$ não foi estatisticamente diferente do tratamento controle $\left(T_{0}\right) \quad(p<0,01)$, o que sugere sua inviabilidade para superar a dormência em sementes de paricá ( $S$. amazonicum) quando comparado aos demais métodos utilizados. Entretanto, os tratamentos $T_{1}$ e $T_{3}$ diferenciaram-se significativamente entre si, e quando comparados com $\mathrm{T}_{0}$ e $\mathrm{T}_{2}$, sendo os valores médios de $T_{3}$ os maiores (Figura 2). Resultados encontrados por MATHEUS \& LOPES (2007), analisando sementes de Erythrina variegata L. foram condizentes com o atual trabalho, sendo identificado também a escarificação mecânica como o método que proporcionou maior número de sementes germinadas. 


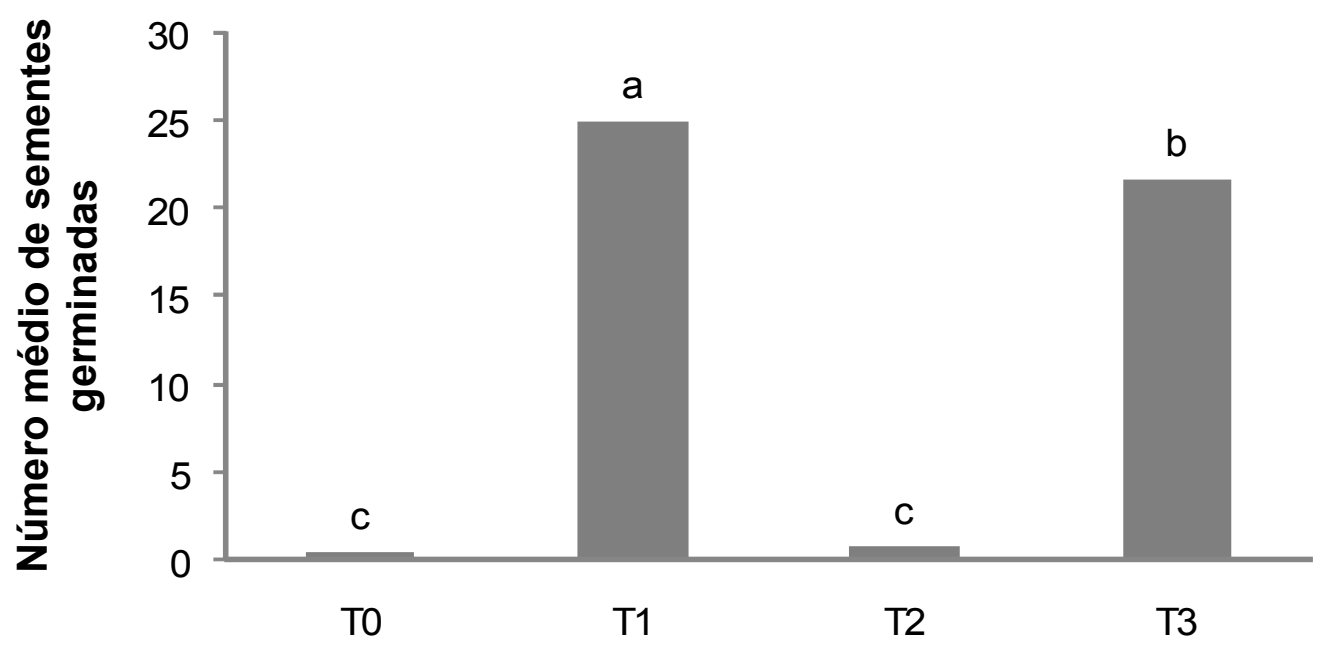

Tratamentos de superação de dormência

FIGURA 2: Número médio de sementes germinadas no final da avaliação de diferentes tratamentos pré-germinativos visando a superação de dormência de paricá (Schizolobium amazonicum). $T_{0}$ - Tratamento controle (testemunha); $\mathrm{T}_{1}$ - Imersão em ácido sulfúrico $\left(\mathrm{H}_{2} \mathrm{SO}_{4}\right)$ durante 60 minutos; $\mathrm{T}_{2}$ - Imersão em água $\left(\mathrm{H}_{2} \mathrm{O}\right)$ durante 24 horas; $\mathrm{T}_{3}$ - Escarificação mecânica. Letras iguais não diferem estatisticamente ao nível de $1 \%$ de probabilidade pelo teste de Scoot-Knoot.

De acordo com SILVA et al. (2011), o método de escarificação mecânica também foi eficiente para superar a dormência em sementes de Sesbania virgata (Cav.) Pers. (sesbânia), obtendo 95\% de germinação. COSTA et al. (2010) estudando diferentes métodos pré-germinativos em sementes de Adenanthera pavonina L. (olho-de-dragão) verificaram que os melhores resultados foram para sementes imersas em ácido sulfúrico (5 e 10 minutos), diferenciando deste trabalho apenas no tempo de imersão, que no caso do presente trabalho foi de 60 minutos.

AVELINO et al. (2012) trabalhando com sementes de jucá (Caesalpinia ferrea Mart. ex Tul. var. ferrea) constataram que as maiores médias foram obtidas com a escarificação mecânica e química, apresentando 66 e $68 \%$ de germinação, respectivamente, resultados inferiores aos encontrados no presente trabalho (100 e $80 \%$, respectivamente), mas que reforça a eficiência destes métodos na superação de dormência em sementes de espécies florestais.

NASCIMENTO et al. (2009), estudando faveira (Parkia platycephala Benth), também encontraram os melhores resultados em sementes que foram submetidas à escarificação mecânica e imersão em ácido sulfúrico. Igualmente aos resultados desta pesquisa, foram os tratamentos de escarificação mecânica e imersão em ácido sulfúrico os responsáveis pelas maiores porcentagens e velocidade de germinação de sementes desde a primeira contagem permanecendo até o final das análises. No entanto, há que 
se considerar a intensidade dos tratamentos e a velocidade de germinação das sementes que foram reduzidas para quatro dias.

\section{CONCLUSÃO}

Os melhores métodos identificados para superar a dormência tegumentar em sementes de paricá (Schizolobium amazonicum) foram a escarificação mecânica e a imersão em ácido sulfúrico $\left(\mathrm{H}_{2} \mathrm{SO}_{4}\right)$ durante 60 minutos, sendo que apenas o primeiro método proporcionou a germinação de $100 \%$ das sementes. Neste trabalho, foi possível reduzir a germinação máxima de sementes de $S$. amazonicum para um período de quatro dias utilizando a escarificação mecânica com a abertura de três estrias nas sementes, o que contribui na redução do tempo e homogeneidade na produção de mudas de espécies florestais que apresentam dormência tegumentar.

\section{REFERÊNCIAS}

ABRAF - ASSOCIAÇÃO BRASILEIRA DE FLORESTAS PLANTADAS. Anuário Estatístico 2012/ano base 2011. Disponível em: http:// www.abraflor.org.br/estatisticas/ ABRAF12/ABRAF12-BR.pdf. Acesso: 04 de fevereiro de 2014.

ALVARES, C. A.; Stape, J. L; Sentelhas P. C.; Gonçalves, J. L de M.; Sparovek, G. Köppen's climate classification map for Brazil. Meteorologische Zeitschrift, v. 22, n. 6, p. 711-728, 2013. DOI: 10.1127/0941-2948/2013/0507. Disponível em: <http://www.lerf.eco.br/img/publicacoes/Alvares_etal_2014.pdf>. Acesso: 06 de outubro de 2015. DOI 10.1127/0941-2948/2013/0507.

AVELINO, J. I.; LIMA, J. S. S.; RIBEIRO, M. C. C.; CHAVES, A. P.; RODRIGUES, G. S. $O$. Métodos de quebra de dormência em sementes de jucá (Caesalpinia ferrea Mart. ex Tul. var. ferrea). Revista Verde, v. 7, n. 1, p.102 - 106, 2012. Disponível em: $<$ http://www.gvaa.com.br/revista/index.php/RVADS/article/view/853/pdf_374>. Acesso em: Acesso: 06 de outubro de 2015.

AZEREDO, G. A. de; PAULA, R. C. de; VALERI, S. V.; F. V. M. Superação de dormência de sementes de Piptadenia moniliformis Benth. Revista Brasileira de Sementes, v. 32 , n. 2 p. 049-058, 2010. Disponível em: <http://www.scielo.br/pdf/rbs/v32n2/v32n2a06.pdf>. Acesso em: 06 de outubro de 2015.

BRASIL. MINISTÉRIO DA AGRICULTURA, PECUÁRIA E ABASTECIMENTO. Regras para Análise de Sementes. Secretaria de Defesa Agropecuária. - Brasília : Mapa/ACS, 399 p. ISBN 978-85-99851-70-8. 2009.

CAIONE G.; LANGE A.; SCHONINGER, E. L. Crescimento de mudas de Schizolobium amazonicum (Huber ex Ducke) em substrato fertilizado com nitrogênio, fósforo e potássio. Scientia Forestalis, v. 40, n. 94, p. 213-221. 2012. Disponível em: <http://www.ipef.br/publicacoes/scientia/nr94/cap08.pdf>. Acesso em: 07/10/15. 
CARVALHO, J. G.; VIÉGAS, I. J. M. Caracterização de Sintomas de Deficiências de Nutrientes em Paricá (Schizolobium amazonicum Huber ex. Ducke). Embrapa: Circular Técnica. ISSN 1517-211X. (Circular Técnica). 2004.

CARVALHO, P. E. R. Paricá: Schizolobium amazonicum. Colombo, PR: Embrapa. ISSN 1517-5278. (Circular Técnica 142). 2007.

CORDEIRO, I. M. C. C.; BARROS, P. L. C. de; LAMEIRA, O. A; GAZEL FILHO, A. B. Avaliação de plantios de paricá (Schizolobium parahyba var. amazonicum (Huber ex Ducke) Barneby de diferentes idades e sistemas de cultivo no município de Aurora do Pará - PA (Brasil). Ciência Florestal, v. 25, n. 3, p. 679-687, 2015. Disponível em: $<$ http://cascavel.ufsm.br/revistas/ojs-

2.2.2/index.php/cienciaflorestal/article/view/19618/11613>. Acesso em: 06 de outubro de 2015.

COSTA, P. A.; LIMA, A. L. S.; ZANELLA, F.; FREITAS, H. Quebra de dormência em sementes de Adenanthera pavonina L. Pesquisa Agropecuária Tropical, v. 40, n. 1, p. 83-88, 2010. DOI: 10.5216/pat.v40i1.4092. Disponível em: <file:///C:/Users/Estudante/Downloads/4092-34741-4-PB\%20(1).pdf>. Acesso em: 07/10/15.

DALLING, J.W.; DAVIS, A.S.; SCHUTTE, B.J.; ARNOLD, A.E. Seed survival in soil: interacting effects of predation, dormancy and the soil microbial community. Journal of Ecology, v. 99, p. 89-95, 2011. DOI: 10.1111/j.1365-2745.2010.01739.x. Disponível em: <http://onlinelibrary.wiley.com/doi/10.1111/j.1365-2745.2010.01739.x/epdf>. Acesso em: 07/10/15.

EL-KASSABY, Y. A.; MOSS, I.; KOLOTELO, D.; STOEHR, M. Seed germination: mathematical representation and parameters extraction. Forest Science, v. 54, p. $220-$ 227. 2008. Disponível em: <file:///C:/Users/Estudante/Downloads/2008\%20El-Kassaby \%20et\%20al\%20For\%20Sci.pdf>. Acesso em: 07/10/2015.

FERREIRA, D. F. Sisvar: A computer statistical analysis system. Ciência e Agrotecnologia, v. 35, n. 6, p. 1039-1042. 2011. Disponível em: <http://www.scielo.br/pdf/cagro/v35n6/a01v35n6.pdf>. Acesso em: 07/10/2015.

IWAKIRI, S.; SILVA, L. S. da, TRIANOSKI, R.; BONDUELLE, G. M.; ROCHA, V. Y. da. Avaliação do potencial de utilização da madeira de Schizolobium amazonicum "Paricá" e Cecropia hololeuca "Embaúba" para produção de painéis cimento-madeira. Cerne, v. 18, n. 2, p. 303-308. 2012. Disponível em: <http://www.scielo.br/scielo.php? script=sci_arttext\&pid=S0104-77602012000200015 > . Acesso em: 07/10/2015.

JOOSEN, R. V. L., KODDE J, WILLEMS LAJ, LIGTERINK W, VAN DER PLAS LHW, HILHORST HWM. Germinator: a software package for high-throughput scoring and curve fitting of Arabidopsis seed germination. The Plant Journal, v. 62, p. 148-159, 2010. DOI: 10.1111/j.1365-313X.2009.04116.x. Disponível em: 
<http://onlinelibrary.wiley.com/doi/10.1111/j.1365-313X.2009.04116.x/epdf>.

Acesso em: 07/10/2015.

KOBORI, N. N.; MASCARIN, G. M.; CICERO, S. M. Métodos não sulfúricos para superação de dormência de sementes de mucuna-preta (Mucuna aterrima). Informativo ABRATES. v. 23, n. 1, 2013. Disponível em: <http://www.abrates.org.br/images/Informativo/v23_n1/03.Kobori_M

\%C3\%A9todos.pdf>. Acesso em: 07/10/2015.

LOBÃO, M. S.; COSTA, D. P.; ALMONACID, M. A. A.; TOMAZELLO FILHO, M. Qualidade do Lenho de áÁrvores de Schizolobium parahyba Var. amazonicum, Acre, Brasil. Floresta e Ambiente, v. 19, n. 3, p. 374-384. 2012. DOI: 10.4322/floram.2012.044. Disponível em: <http://floram.org/files/v19n3/v19n3a13.pdf>. Acesso em: 07/10/2015.

MATHEUS, M. T.; LOPES, J. C. Morfologia de frutos, sementes e plântulas e germinação de sementes de Erythrina variegata L. Revista Brasileira de Sementes, v. 29, n. 3, p. 8-15, 2007. Disponível em: <http://www.scielo.br/pdf/rbs/v29n3/a02v29n3.pdf>. Acesso em: 07/10/2015.

MEIRELES, R. C.; ARAUJO, E. F.; REIS, M. S.; SEDIYAMA, C. S.; SAKIYAMA, N. S.; REIS, L. S. dos. Secafé: metodologia para acelerar a germinação das sementes de café. Revista Brasileira de Sementes, v. 9, n. 3, p. 90-96. 2007. Disponível em: < http://www.scielo.br/pdf/rbs/v29n3/a12v29n3.pdf>. Acesso em: 09/10/15.

MONTEIRO, K. F. G.; KERN, D. C.; RUIVO, M. de L. P.; RODRIGUES, T. E.; COMETTI, J. L. S. Uso de resíduos de madeira como alternativa de melhorar as condições ambientais em sistema de reflorestamento. Acta Amazonica, v. 40, n. 3, p. 409 - 414. 2010. Disponível em: <http://www.scielo.br/pdf/aa/v40n3/01.pdf>. Acesso em: 07/10/2015.

NASCIMENTO, I. L.; ALVES, E. U.; BRUNO, R. L. A.; GONÇALVES, E. P.; COLARES, P. N. Q.; MEDEIROS, M. S. Superação da dormência em sementes de faveira (Parkia platycephala benth). Revista Árvore, v. 33, n. 1, p. 35-45. 2009. Disponível em: <http:// www.scielo.br/pdf/rarv/v33n1/v33n1a05.pdf>. Acesso em: 07/10/2015.

PEREIRA, S. R.; LAURA, V. A.; SOUZA, A. L. T de. Superação de dormência de sementes como estratégia para restauração florestal de pastagem tropical. Pesquisa Agropecuária Brasileira, Brasília, v. 48, n. 2, p. 148-156, 2013. DOI: 10.1590/S0100204X2013000200004. Disponível <http://www.scielo.br/pdf/pab/v48n2/48n02a04.pdf>. Acesso em: 07/10/2015.

PUKACKA, S.; RATAJCZAK, E. Factors influencing the storability of Fagus sylvatica L. seeds after release from dormancy. Plant Growth Regulation, v. 72, p. 17-27. 2014. DOI 10.1007/s10725-013-9832-5. 
SHIMIZU, E. S. C.; PINHEIRO, H. A.; COSTA, M. A.; SANTOS FILHO, B. G. Aspectos fisiológicos da germinação e da qualidade de plântulas de Schizolobium amazonicum em resposta à escarificação das sementes em lixa e água quente. Revista Árvore, v. 35, n. 4, p. 791-800, 2011. Disponível em: <http://www.scielo.br/pdf/rarv/v35n4/a04v35n4.pdf>. Acesso em: 07/10/2015.

SILVA, P. E. M.; SANTIAGO, E. F.; DALOSO, D. M.; SILVA, E. M.; SILVA, J. O. Quebra de dormência em sementes de Sesbania virgata (Cav.) Pers. IDESIA, v. 29, n. 2, p. 3945,. 2011. Disponível em: <http://www.scielo.cl/pdf/idesia/v29n2/art05.pdf>. Acesso em: 07/10/2015.

VIDAURRE, G. B.; CARNEIRO, A. de C. O.; VITAL, B. R.; SANTOS, R. C. dos; VALLE, M. L. A. Propriedades energéticas da madeira e do carvão de paricá (Schizolobium amazonicum). Revista Árvore, v. 36, n. 2, p. 365-371,. 2012. Disponível em: <http://www.scielo.br/pdf/rarv/v36n2/a18v36n2.pdf>. Acesso em: 07/10/2015. 